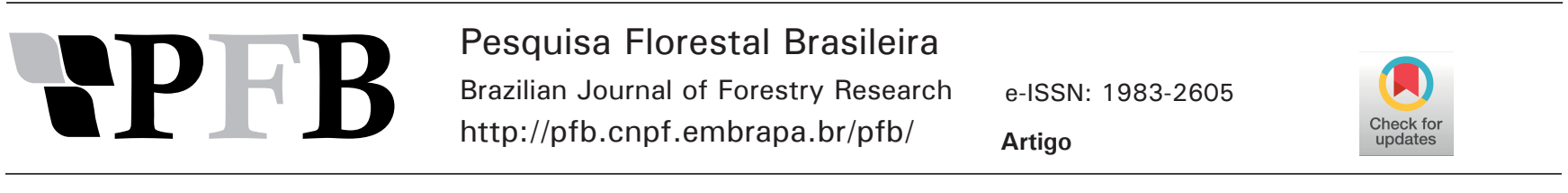

\title{
Óleos essenciais e benzilaminopurina (BAP) para o cultivo in vitro de Dimorphandra mollis
}

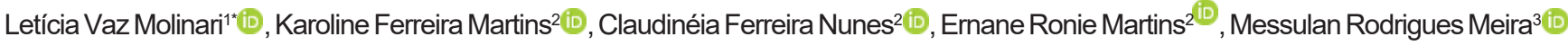 \\ ${ }^{1}$ Universidade Federal de Lavras, Aquenta Sol, C.P. 3037, CEP 37200-000, Lavras, MG, Brasil \\ ${ }^{2}$ Universidade Federal de Minas Gerais, Centro de Pesquisa em Ciências Agrárias, Avenida Universitária, n. 1000, Bairro Universitário, CEP 39404-547, Montes \\ Claros, MG, Brasil \\ ${ }^{3}$ Universidade Estadual do Sudoeste da Bahia, Campus Universitário Juvino Oliveira, BR 415, km 04, CEP 45700-000, Itapetinga, BA, Brasil
}

"Autor correspondente:
leticia_vaz03@hotmail.com

Termos para indexação:

Compostos voláteis

Sanitizante

Fitoregulador

Index terms:

Volatile compounds

Sanitizer

Phytoregulator

Histórico do artigo:

Recebido em 03/04/2019

Aprovado em 09/12/2020

Publicado em 14/09/2021

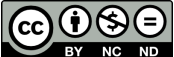

Resumo - A micropropagação é uma alternativa para a conservação genética de espécies endêmicas do Cerrado, como Dimorphandra mollis (fava-d'anta), possibilitando a maximização da propagação em elevada qualidade. Para solucionar os fatores limitantes ao cultivo in vitro de $D$. mollis, o presente trabalho teve como objetivo avaliar a eficiência de óleos essenciais como sanitizante e testar concentrações de regulador de crescimento benzilaminopurina (BAP) na fase de multiplicação in vitro. Sementes coletadas em população natural foram escarificadas e desinfestadas com hipoclorito de sódio e óleos essenciais de Lippia origanoides, Ocimum gratissimum, L. rotundifolia e Cymbopogon citratus, sendo posteriormente inoculadas em meio de cultura MS. A multiplicação in vitro foi avaliada em quatro concentrações de BAP $\left(0,5 ; 1,0 ; 1,5\right.$ e $\left.2,0 \mathrm{mg} \mathrm{L}^{-1}\right)$. O óleo essencial de $C$. citratus se mostrou o mais adequado para a desinfestação de sementes da fava d'anta, na fase de estabelecimento in vitro. Fitoreguladores utilizados no presente estudo não promoveram resultados satisfatórios para definir um protocolo de multiplicação in vitro para a espécie.

\section{Essential oils and benzylaminopurine (BAP) for multiplication in vitro of Dimorphandra mollis}

\begin{abstract}
Micropropagation is an alternative for genetic conservation of Cerrado endemic species, such as Dimorphandra mollis (fava-d'anta), making possible maximizing propagation in high quality. To solve the limiting factors of in vitro cultivation of $D$. mollis, the present study aimed to evaluate the efficiency of essential oils as a sanitizer and to test concentrations of benzylaminopurine growth regulator (BAP) in the in vitro multiplication phase. Seeds collected from a natural population were scarified and disinfected with sodium hypochlorite and essential oils of Lippia origanoides, Ocimum gratissimum, L. rotundifolia and Cymbopogon citratus. The seeds were inoculated in MS culture medium. In vitro multiplication was evaluated using four concentrations of $\operatorname{BAP}\left(0.5 ; 1.0 ; 1.5\right.$ and $\left.2.0 \mathrm{mg} \mathrm{L}^{-1}\right)$. Essential oil of C. citratus is the most suitable for disinfestation of fava d'anta seeds, in the stage of establishment in vitro. Phytoregulators used in the present study did not provide satisfactory results to define an in vitro multiplication protocol for the species.
\end{abstract}




\section{Introdução}

Dimorphandra mollis Benth, popularmente conhecida como fava d'anta, pertence à família Fabaceae. É uma espécie lenhosa, de porte arbóreo, medindo de 3 a $7 \mathrm{~m}$ de altura e de hábito xerófito (Souza et al., 2017). Seus frutos são semideiscentes, achatados, com até $15 \mathrm{~cm}$ de comprimento, e com mesocarpo farináceo e adocicado (Barros et al., 2017). O valor atribuído à espécie se deve à presença de flavonoides que ocorrem no epicarpo e mesocarpo do fruto (Gonçalves et al., 2010).

Dentre os glicosídeos flavônicos, destacam-se rutina e quercetina. A rutina é um flavonoide glicosilado portador de vitamina $\mathrm{P}$, a qual em associação à vitamina $\mathrm{C}$, atua no fortalecimento e permeabilidade das paredes dos vasos capilares, por reduzir a concentração do colesterol LDL - low-density lipoprotein (Gonçalves et al., 2010). Devido às suas propriedades, esse flavonoide é comercializado como fitoterápico para o tratamento de distúrbios vasculares e hipertensão. Além disso, também possuem atividade antioxidante, efeitos antiinflamatórios e antitumorais (Freitas et al., 2011; Aziza et al., 2014; $\mathrm{Ku}$ et al., 2014; Mascaraque et al., 2014; Costa et al., 2016).

A rutina e a quercetina são produzidas durante o desenvolvimento da semente, precisamente no estágio de maturação, tendo seu maior teor antes da dessecação, ou seja, ainda no fruto verde e na planta mãe. Portanto, a coleta dos frutos verdes é ideal para maior produtividade desses glicosídeos, o que compromete a manutenção do banco de sementes para a perpetuação da espécie, por ser uma planta nativa altamente explorada (Nunes et al., 2012).

Embora esse procedimento para a colheita dos frutos seja uma fonte de renda para os extrativistas, a coleta predatória, bem como a falta de plantio comercial, coloca e espécie em vulnerabilidade (Nunes et al., 2012). Uma alternativa para a conservação genética e multiplicação desta espécie é a micropropagação. Esta técnica apresenta inúmeras vantagens, tais como a produção de milhares de plantas a partir de um único propágulo, possibilidade de fixação de ganhos genéticos em populações clonais e maximização da propagação de plantas com alta qualidade, tudo isso em um pequeno espaço físico e em curto tempo, independente de fatores climáticos limitantes (Righeto et al., 2012, Trueman et al., 2018).

No entanto, o seu cultivo ainda é um desafio, requerendo cuidados específicos nas etapas de germinação, crescimento e desenvolvimento até a obtenção de uma planta completa. Para entender os fatores limitantes de cada fase do cultivo in vitro da espécie, faz-se necessário ampliar os estudos que tratam da cultura de tecidos vegetais de espécies florestais (Oliveira et al., 2013). Dentre as demandas da técnica está a assepsia das sementes com o produto comercial hipoclorito de sódio e o uso de reguladores de crescimento. Porém, em se tratando de espécies florestais nativas, existe carência de métodos de desinfestação para testes de germinação, bem como a concentração ideal de fitorreguladores na fase de estabelecimento.

Os óleos essenciais surgem como alternativa potencial no controle de microorganismos fitopatogênicos de material vegetal, devido à sua forte atuação como biossanitizante (Carvalho et al., 2011; Machado et al., 2015; Souza et al., 2015; Miranda et al., 2016). Neste contexto, estudos sobre a desinfestação de sementes e o efeito das diferentes concentrações de fitoreguladores no processo de micropropagação são inexistentes.

Em vista da necessidade de conservação genética de D. mollis, é importante desenvolver protocolos específicos para a sua micropropagação. O presente trabalho teve como objetivo avaliar a eficiência dos óleos essenciais como sanitizante na fase de estabelecimento in vitro e concentrações do regulador de crescimento benzilaminopurina (BAP) na fase de multiplicação in vitro.

\section{Material e métodos}

Os experimentos foram realizados no Laboratório de Biotecnologia do Centro de Pesquisa em Ciências Agrárias do Instituto de Ciências Agrárias da Universidade Federal de Minas Gerais (CPCA-UFMG). As sementes de Dimorphandra mollis foram coletadas em população natural, no município de Montes Claros, MG (16 45'16,11' S e 4353'38,7” W). Os acessos de Lippia origanoides Kunth., Ocimum gratissimum L., L. rotundifolia Cham. e Cymbopogon citratus (DC.) Stapf, para a extração do óleo essencial, foram obtidos do Horto Medicinal do Instituto de Ciências Agrárias da UFMG (16 40'50,92" S e 4350'22,36” W). Essas espécies aromáticas estão registradas no Sistema Nacional de Gestão do Patrimônio Genético e do Conhecimento Tradicional Associado (SisGen), sob os números de registro: A48990E, AE95BA0, A84E567 e A05b21D, respectivamente. 
Para a coleta dos frutos, foram selecionadas matrizes de populações naturais, contendo frutos maduros e sadios depositados sobre o solo, com o propósito de estimular a estratégia de manutenção do banco de sementes das árvores matrizes.

\section{Extração dos óleos essenciais}

As folhas das espécies aromáticas (L. rotundifolia, O. gratissimum, L. origanoides, e C. citratus) foram pesadas e submetidas à estufa de circulação forçada de ar a $45{ }^{\circ} \mathrm{C}$, até peso constante. Concluída essa etapa, $100 \mathrm{~g}$ de material vegetal foi submetido à extração dos óleos essenciais por $4 \mathrm{~h}$, pelo método de hidrodestilação em aparelho tipo Clevenger, conforme metodologia adaptada de Silva et al. (2016). Na sequência, os óleos essenciais foram acondicionados à $-10^{\circ} \mathrm{C}$ até o momento dos ensaios.

\section{Estabelecimento in vitro}

As sementes foram escarificadas mecanicamente (fricção manual da semente do lado oposto ao micrópilo com lixa número 120 até o início da exposição do endosperma), e lavadas em água corrente durante 1 min. Posteriormente, foram lavadas por três vezes em água deionizada autoclavada e imersas em solução hidroalcoólica a $70 \%(\mathrm{v} / \mathrm{v})$ por $30 \mathrm{~s}$ com agitação constante, dentro da câmara de fluxo laminar horizontal. Em seguida, as sementes foram imersas em solução de $\mathrm{NaOCl}$ a $1,0 \%(\mathrm{v} / \mathrm{v})$, Clarix ${ }^{\circledR}$ e óleos essenciais obtidos das respectivas espécies aromáticas, durante $15 \mathrm{~min}$. Finalmente, as sementes foram lavadas em água deionizada e autoclavada, por cinco vezes, sendo inoculadas sob condições assépticas, em tubos de ensaio $(25 \times 150 \mathrm{~mm})$ contendo $10 \mathrm{~mL}$ do meio de cultura.

O meio de cultura básico utilizado nos experimentos foi MS (Murashige \& Skoog, 1962), adicionado de $30 \mathrm{~g} \mathrm{~L}^{-1}$ de sacarose (Synth Ltda), $7 \mathrm{~g} \mathrm{~L}^{-1}$ de ágar (Merck S.A.) e $1 \mathrm{~g} \mathrm{~L}^{-1}$ de polivinilpirrolidona (PVP). $\mathrm{O} \mathrm{pH}$ do meio de cultura foi ajustado para 5,8 $\pm 0,05$, antes da adição do ágar. A autoclavagem do meio de cultura foi realizada a $127^{\circ} \mathrm{C}$ e pressão de $1,5 \mathrm{kgf} \mathrm{cm}^{-2}$, durante $20 \mathrm{~min}$.

As sementes foram mantidas por 30 dias em câmara de germinação tipo BOD (Biochemical Oxigen Demand), a $25^{\circ} \mathrm{C}$ e fotoperíodo de $12 \mathrm{~h}$, com ausência de luz nos primeiros sete dias de cultivo, visando reduzir o processo oxidativo (Dutra et al., 2009).

O experimento foi disposto em delineamento inteiramente casualizado, sendo os tratamentos constituídos pelos óleos essenciais de L. rotundifolia, O. gratissimu, L. origanoides, C. citratus como desinfestantes e o hipoclorito de sódio como controle, com 15 repetições, compostas de uma semente em cada.

$O$ índice de velocidade de germinação (IVG) foi calculado de acordo com a fórmula de Maguire (1962). A porcentagem de germinação, a contaminação e oxidação, o comprimento da parte aérea $(\mathrm{cm})$, o número de brotos e o número de raízes foram avaliados aos 21 dias de cultivo.

\section{Multiplicação in vitro}

Após a germinação das sementes e estabelecimento in vitro aos 21 dias de cultivo, foram isolados e preparados segmentos nodais padronizados com um par de gemas axilares. Esses foram inoculados sob condições assépticas em tubos de ensaio $(25 \times 150 \mathrm{~mm})$, contendo $15 \mathrm{~mL}$ do meio de cultura MS, adicionados de $30 \mathrm{~g} \mathrm{~L}^{-1}$ de sacarose (Synth Ltda), $7 \mathrm{~g} \mathrm{~L}^{-1}$ de ágar (Merck S.A.) e suplementado com $0,5 \mathrm{mg} \mathrm{L}^{-1}$ de ácido indol-3-butírico (AIB) e diferentes concentrações de benzilaminopurina.

$\mathrm{O}$ experimento foi disposto em delineamento inteiramente casualizado, sendo quatro concentrações de benzilaminopurina (BAP) $(0 ; 0,5 ; 1,0 ; 1,5$ e $\left.2,0 \mathrm{mg} \mathrm{L}^{-1}\right)$, com 15 repetições compostas de um explante cada.

O número de brotos, número de folhas por brotos, comprimento da parte aérea $(\mathrm{cm})$, presença e ausência de raízes, bem como presença e ausência de calos, foram avaliados aos 45 e 75 dias de cultivo.

\section{Análise dos dados}

Os dados do estabelecimento dos explantes foram submetidos à normalização, a partir da transformação em arco seno $\sqrt{ }(x+0,5)$ e da medição utilizando o log $(\mathrm{x}+1)$. Posteriormente, foram submetidos à análise de variância, sendo as médias comparadas pelo teste de Tukey a 5\% de significância. Os dados da multiplicação in vitro, tiveram suas médias comparadas por regressão polinomial $(\mathrm{p} \leq 0,05)$. Para a presença e ausência de calos e raízes, utilizou-se a regressão Probit ${ }^{\circledR}(U F V, 2017)$.

\section{Resultados}

A manutenção das sementes no escuro nos primeiros setes dias do estabelecimento in vitro mostrou-se eficiente, pois não se observou escurecimento do meio de cultura, nem das sementes de Dimorphandra mollis. As sementes desinfestadas com Cymbopogon citratus 
iniciaram a germinação sete dias após a inoculação, sendo que aos 21 dias apresentaram a maior porcentagem de germinação (91,67\%). Resultado diferente foi obtido com o uso do óleo essencial de Lippia rotundifolia, pois não houve germinação das sementes e registrou-se o segundo maior percentual de contaminação (Tabela 1).

O maior índice de contaminantes foi verificado no tratamento com Ocimum gratissimum. Embora o óleo essencial dessa espécie não tenha apresentado eficiência na desinfestação, apresentou o maior índice de velocidade de germinação (IVG), com média de $0,67 \%$. Enquanto que o tratamento referente ao óleo de Lippia rotundifolia apresentou $\mathrm{IVG}=0$, ou seja, não ocorrência de germinação.

Para as variáveis comprimento da raiz, comprimento da parte aérea e número de raízes, o tratamento com óleo essencial de Cymbopogon citratus apresentou o melhor resultado, refletindo no melhor desenvolvimento e crescimento das plântulas.

Quanto à multiplicação dos explantes, observou-se diferença significativa com o uso do benzilaminopurina (BAP), para o comprimento da parte aérea, aos 45 e 75 dias de cultivo. Enquanto que, para o número de brotos, não apresentou diferença, uma vez que houve emissão de brotos no tratamento controle.

Tabela 1. Atributos médios do estabelecimento e multiplicação in vitro das sementes de Dimorphandra mollis Benth. submetidas a agentes desinfestantes.

Table 1. Mean attributes of the in vitro multiplication factor of the seeds of Dimorphandra mollis Benth. submitted to disinfestation agents.

\begin{tabular}{|c|c|c|c|c|c|c|c|}
\hline TRATAMENTO & SG (\%) & SC (\%) & IVG & CR & CPA & NF & NR \\
\hline Lippia rotundifolia & $0,00^{\mathrm{cns}}$ & $91,67^{\mathbf{a b}^{* * k}}$ & $0,00^{\text {ens }}$ & $0,00^{\mathrm{cns}}$ & $0,00^{\mathrm{cns}}$ & $0,00^{\text {bns }}$ & $0,00^{\text {bns }}$ \\
\hline Ocimum gratissimu & $25,00^{\mathbf{b e k *}}$ & $100,00^{\mathrm{a}^{* *}}$ & $0,67^{a^{* *}}$ & $0,77^{\mathrm{be}^{\mathrm{k} * k}}$ & $0,93^{\mathrm{e}^{* * *}}$ & $0,17^{\mathrm{b}^{* *}}$ & $0,33^{b^{* *}}$ \\
\hline Lippia origanoides & $41,67^{\mathbf{b}^{k * k}}$ & $58,33^{\mathrm{bekt}}$ & $0,60^{\mathrm{b**}}$ & $1,55^{b^{\mathrm{c}^{* k}}}$ & $1,07^{\mathrm{be}^{\mathrm{c} *}}$ & $0,25^{\mathrm{ab}^{* * *}}$ & $1,168^{b^{\text {t**}}}$ \\
\hline Cymbopogon citratus & $91,67^{a^{* * *}}$ & $33,33^{\mathbf{c d}^{* *}}$ & $0,45^{\mathrm{d}^{\mathrm{k}}}$ & $3,90^{\mathrm{a}^{* k}}$ & $4,05^{\mathrm{a}^{* *}}$ & $1,50^{\mathrm{a}^{* *}}$ & $4,83^{a^{* k}}$ \\
\hline Hipoclorito & $58,33^{\mathbf{a b}^{k *}}$ & $0,00^{\mathrm{d}^{* *}}$ & $0,06^{\text {ekt }}$ & $3,10^{\mathbf{a b}^{\star * *}}$ & $3,308^{\mathbf{a b}^{\star k *}}$ & $0,50^{\mathrm{ab}^{* k *}}$ & $2,17^{a^{b^{* *}}}$ \\
\hline
\end{tabular}

** Médias com letras iguais, em uma mesma coluna, não diferem estatisticamente entre si, pelo Teste de Tukey a $5 \%$ de probabilidade. SG $=$ sementes germinadas; $\mathrm{SC}=$ sementes contaminadas; $\mathrm{IVG}=$ taxa de germinação; $\mathrm{CR}=$ comprimento da raíz; $\mathrm{CPA}=$ comprimento da parte aérea; $\mathrm{NF}=$ número de folhas; $\mathrm{NR}=$ número de raízes.

As variáveis comprimento da parte aérea e número de folhas apresentaram comportamento quadrático (Figura 1), onde a concentração de BAP de $1,0 \mathrm{mg} \mathrm{L}^{-1}$, proporcionou resposta favorável tanto para o comprimento, quanto para o número de folhas. Para as duas variáveis, houve tendência de redução quando na presença de concentrações mais elevadas do regulador BAP (Figuras 1A e 1B).
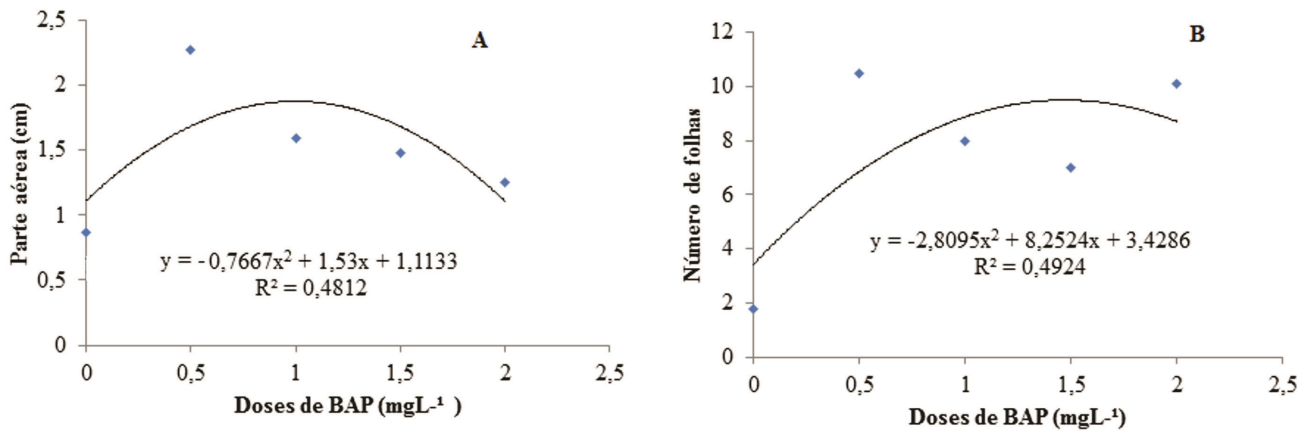

Figura 1. Efeito de concentrações de benzilaminopurina (BAP) sobre o comprimento da parte aérea (A) e número de folhas (B) de propágulos de Dimorphandra mollis aos 45 e 75 dias de cultivo in vitro, respectivamente.

Figure 1. Effect of benzilaminopurina (BAP) concentrations on shoot length (A) and number of leaves (B) of propagules of Dimorphandra mollis at 45 and 75 days of in vitro culture. 
Aos 45 dias de cultivo, não se observou diferença significativa entre os tratamentos, os quais apresentaram média de 7,6 folhas por explante. Aos 75 dias de cultivo, o número de folhas aumentou para 10,5. Esse resultado evidencia a resposta da citocinina influenciada pelas concentrações. A concentração de $0,50 \mathrm{mg} \mathrm{L}^{-1}$ de BAP proporcionou quantidade superior de folhas.

Para as duas avaliações, aos 45 e 75 dias após a multiplicação dos explantes, não houve presença de raízes, mas de calo, cujo surgimento foi visível em todos os tratamentos, independente da concentração de BAP utilizada.

\section{Discussão}

A germinação in vitro e consequente formação de plântulas completas é uma metodologia satisfatória para a obtenção de materiais vegetais que servirão de fonte de explantes. Porém, eventos indesejáveis são enfrentados durante o estabelecimento dos materiais in vitro, como a contaminação e a oxidação. Para muitas espécies florestais, existem protocolos de desinfestação já desenvolvidos e em uso (Gomes-Copeland et al., 2017; Teixeira et al., 2018; Yarra et al., 2016). No entanto, para espécies nativas e endêmicas do cerrado, as pesquisas são inexistentes o que dificulta a propagação clonal e conservação desses materiais.

A eficiência do óleo essencial de Cymbopogon citratus na desinfestação das sementes pode ser atribuída aos principais componentes encontrados nesse óleo essencial, sendo eles: citral, geraniol e mirceno. Esses compostos, em sinergismo, apresentam boa atividade biológica e alto potencial antimicrobiano contra bactérias gram positivas e fungos patogênicos (Pereira et al., 2004; Santos et al., 2009; Guimarães et al., 2011; Mirghani et al., 2012; Raut \& Karuppayil, 2014; Machado et al., 2015).

Diante do resultado observado (Tabela 1) e da atividade biológica atribuída ao óleo essencial da espécie, essa pode ser utilizada como agente desinfestante. Para Carvalho et al. (2011), o que se espera de um agente desinfestante é que apresente eficiência na remoção dos microrganismos presentes na superfície dos explantes, de forma a viabilizar o cultivo. Garrido Pinheiro et al. (2016) corroboram os autores ao reportarem que uma boa assepsia dos explantes reduz a contaminação e proporciona melhores desempenhos na germinação. Dessa forma, o resultado está dentro do preconizado na literatura, sendo possível considerarmos o óleo de C. citratus como um desinfestante em potencial para cultivo in vitro de espécies florestais nativas.

Além da atividade antimicrobiana, C. citratus possui atividade antifúngica comprovada (Bozik et al., 2017; Kasmi et al., 2017; Sharma et al., 2017; Xie et al., 2017). Propriedades antifúngicas e antibacterianas também estão presentes no óleo essencial de L. origanoides e L. rotundifolia, principalmente por terem carvacrol, timol, mirceno e cariofileno em sua composição química (Tangarife-Castaño et al., 2012).

Em sementes de espécies nativas, é comum a presença de microrganismos que dificultam a germinação (Berghetti et al., 2015). Por isso, a associação dos óleos essenciais à fase de assepsia das sementes contribuiu para reduzir a carga microbiana (Almeida et al., 2016; Souza et al., 2015), possibilitando o estabelecimento in vitro da planta.

Scalon et al. (2007), trabalhando com Dimorphandra mollis em diferentes ambientes de incubação, observaram índice de velocidade de germinação (IVG) de 1,22 a $25{ }^{\circ} \mathrm{C}$; 0,31 entre 20 a $30{ }^{\circ} \mathrm{C}$ e 1,33 para casa de vegetação em temperatura ambiente. Assim, o baixo IVG obtido no presente estudo pode ser devido ao armazenamento prolongado das sementes, prática que pode ter influenciado na qualidade e o vigor das mesmas. Essa observação corrobora os estudos de Biruel et al. (2007) e Freitas et al. (2011) com outras espécies, onde os autores observaram resultados semelhantes.

Garrido Pinheiro et al. (2016), trabalhando com Bauhinia forficata, obtiveram maior comprimento das plântulas utilizando como agente desinfestante o $\mathrm{NaClO}$ a $2 \%$ por $1 \mathrm{~min}$. Os mesmos autores, trabalhando com Cedrela fissilis, observaram maior comprimento da parte aérea utilizando $\mathrm{NaClO} 1 \%$ por 3 min. Nascimento et al. (2007), estudando Parapiptadenia rigida, observaram que sementes desinfestadas com 2,5 e $5,0 \%$ de $\mathrm{NaClO}$ durante 30 e $15 \mathrm{~min}$, respectivamente, apresentaram maior porcentagem de germinação e menores porcentagens de contaminação fúngica ou bacteriana.

A eficiência do polivinilpirrolidona (PVP) no meio de cultura, o torna indispensável para o protocolo de cultivo de espécies nativas ricas em polifenóis. Resende et al. (2015) reportaram esse antioxidante como um polímero amorfo benéfico para esse fim, pois além de reduzir os efeitos tóxicos de compostos fenólicos, não possui atividade fisiológica sobre as células. Essa afirmativa é confirmada pelo uso do antioxidante em 
Lippia sidoides, espécie rica em fenóis totais que apresentou baixa oxidação usando concentração de PVP de $0,5 \mathrm{~g} \mathrm{~L}^{-1}$ (Costa et al., 2007). No estabelecimento in vitro de $L$. rotundifolia, $1,0 \mathrm{~g} \mathrm{~L}^{-1}$ de PVP mostrou-se suficiente para controlar a oxidação do meio (Resende et al., 2015). O que se observa é que a família das Fabaceae é difícil de ser regenerada in vitro, principalmente devido à sua característica recalcitrante em relação ao uso dessa técnica (Jha et al., 2004; Yarra et al., 2016), ou seja, aos estímulos oferecidos via meio de cultura e condições de cultivo. Portanto, definir protocolo eficiente depende de diferentes fatores, dentre eles, a escolha do explante e as concentrações adequadas do fitorregulador (Almeida et al., 2015). Quando esses fatores forem bem estabelecidos, será possível induzir uma resposta fisiológica, como a formação de brotos e multiplicação in vitro de espécies como $D$. mollis.

Durante a fase de multiplicação, o aparecimento de calo pode não ser um problema, desde que se consiga reduzir o surgimento dos mesmos nos próximos subcultivos e que não impeça o surgimento e a diferenciação das raízes (Bezerra et al., 2014). A formação de calos em espécies lenhosas é um evento frequente, podendo inibir ou não o desenvolvimento das culturas in vitro. No presente trabalho, os calos desenvolvidos na base dos segmentos nodais não apresentaram competência para se diferenciarem em raízes, consequentemente, não correspondendo à formação completa de uma nova planta.

Respostas similares para a variável comprimento da parte aérea foram observadas por Gomes-Copeland et al. (2017) e Vicente et al. (2009), trabalhando com Conobea scoparioides e Vernonia condensata, respectivamente, com a concentração de $1 \mathrm{mg} \mathrm{L}^{-1}$. O presente estudo revelou que, para $D$. mollis, doses maiores da citocinina BAP inibiram o alongamento da parte aérea. Possivelmente, essa resposta fisiológica pode ter ocorrido devido ao BAP não ser o regulador de crescimento responsável pelo alongamento celular (Cid, 2014).

Doses crescentes de BAP até a concentração ótima podem resultar em aumento no número de folhas. O ajuste da equação de regressão permitiu inferir que a concentração ótima testada foi de 1,46 $\mathrm{mg} \mathrm{L}^{-1}$ para número de folhas. Concentrações superiores promoveram a redução dessa variável, sendo consideradas não desejáveis para estimular a formação de folhas (Figura 1). Essa observação é corroborada por
Bezerra et al. (2014), ao reportarem que concentrações muito elevadas de citocininas, associadas à condições de cultivo, podem inibir o crescimento e desenvolvimento de folhas. No entanto, resultados diferentes foram apresentados por Freitas et al. (2016) com Justicia pectoralis, que observaram aumento no número de folhas ao elevarem as concentrações da citocinina.

Para D. mollis, as concentrações testadas do BAP não foram suficientemente adequadas para estimular uma resposta fisiológica de produção de brotos. Esse resultado pode ser devido à adição da citocinina (BAP) e auxina (AIB), em concentrações desproporcionais, que não resultaram em relação favorável, sendo esta a explicação para a ocorrência de calos na base dos propágulos. O BAP, como citocinina, é uma substância reguladora responsável pela divisão celular e que, em pequenas concentrações é capaz de induzir uma resposta fisiológica satisfatória, como por exemplo, a formação de novas brotações (Cheng et al., 2013).

Estudos mostram que uma alta relação citocinina e auxina favorece a formação de brotações; e que o inverso promove a formação de raízes; e a combinação de ambos os reguladores em altas concentrações favorecem a formação de calos (Trueman et al., 2018). Assim, podese dizer que a alta relação entre a citocinina BAP e a auxina AIB utilizada no presente estudo, não promoveu resultados satisfatórios para definir um protocolo de multiplicação in vitro para a espécie.

\section{Conclusões}

O óleo essencial de Cymbopogon citratus é o mais adequado para a desinfestação de sementes de Dimorphandra mollis, sendo uma alternativa para estabelecimento in vitro da espécie. No entanto, o regulador de crescimento benzilaminopurina (BAP), em concentrações de até $2,0 \mathrm{mg} \mathrm{L}^{-1}$, não apresenta eficiência para a multiplicação in vitro.

\section{Agradecimentos}

Este trabalho foi realizado com o apoio da Coordenação de Aperfeiçoamento de Pessoal de Nível Superior Brasil (CAPES) - Código de Financiamento 001 e Fundação de Amparo à Pesquisa do Estado de Minas (FAPEMIG). O Instituto de Ciências Agrárias da Universidade Federal de Minas Gerais cedeu a estrutura 
física dos seus laboratórios, equipamentos e reagentes necessários para finalizar esse trabalho.

\section{Referências}

Almeida, M. et al. Plant morphogenesis: theorical basis. Advances in Forestry Science, v. 2, n. 1, p. 13-22, 2015.

Almeida, A. C. de et al. Atividade antisséptica do óleo essencial de Lippia origanoides Cham. (Alecrim-pimenta) na presença de leite bovino. Pesquisa Veterinária Brasileira, v. 36, n. 9, p. 905-911, 2016. http://dx.doi.org/10.1590/S0100-736X2016000900018.

Aziza, S. A. H. et al. Ameliorating role of rutin on oxidative stress induced by Iron overload in hepatic tissue of rats. Pakistan Journal of Biological Sciences, v. 17, n. 8, p. 964-977, 2014.

Barros, T. C. de et al. In the interface of caesalpinioids and mimosoids: Comparative fl oral development elucidates shared characters in Dimorphandra mollis and Pentaclethra. American Journal of Botany, v. 104, n. 2, p. 218-232, 2017. http://dx.doi. org/ 10.3732/ajb.1600308.

Berghetti, A. L. P. et al. Morfologia de Plântulas e Controle de Patógenos em Sementes de Cordia trichotoma. Floresta e Ambiente, v. 22, n. 1, p. 99-106, 2015. http://dx.doi.org/10.1590/21798087.076614 .

Bezerra, R. M. D. F. et al. Efeito de 6-Benzilaminopurina sobre a propagação in vitro de Mimosa caesalpiniifolia Benth. (Fabaceae). Revista Árvore, v. 38, n. 5, p. 771-778, 2014. http://dx.doi. org/10.1590/S0100-67622014000500001.

Biruel, R. P. et al. Germinação de sementes de pau-ferro submetidas a diferentes condições de armazenamento, escarificação química, temperatura e luz. Revista Brasileira de Sementes, v. 29, n. 3, p. 151-159, 2007.

Bozik, M. et al. Selected essential oil vapours inhibit growth of Aspergillus spp. in oats with improved consumer acceptability. Industrial Crops and Products, v. 98, p. 146-152, 2017. http:// dx.doi.org/10.1016/j.indcrop.2016.11.044.

Carvalho, A. C. P. P. de et al. Glossário de cultura de tecidos de plantas. Plant Cell Culture \& Micropropagation, v. 7, n. 1, p. 30-60, 2011.

Cid, L. P. B. Cultivo in vitro de plantas. 3. ed. Brasília, DF: Embrapa, 2014. 325 p.

Cheng, Z. J. et al. Paternof auxin and cytokinin responses for shoot meristema induction results from the regulation of cytokinin biosynthesis by AUXIN RESPNSES FACTOR 3. Plant Physiology, v. 161, n. 1, p. 240-251, 2013.

Costa, A. S. da et al. Estabelecimento de alecrim-pimenta in vitro. Horticultura Brasileira, v. 25, n. 1, p. 68-72, 2007.

Costa, S. L. et al. Impact of plant-derived flavonoids on neurodegenerative diseases. Neurotox Res, v. 30, p. 41-52, 2016. http://dx.doi.org/ 10.1007/s12640-016-9600-1.

Dutra, L. F. et al. A Micropropagação de Eucalipto. Pesquisa Florestal Brasileira, v. 1, n. 58, p. 49-59, 2009. http://dx.doi. org/10.4336/2009.pfb.58.49.
Freitas, R. M. O. de et al. In vitro propagation of Justicia pectoralis. Revista Verde de Agroecologia e Desenvolvimento Sustentável, v. 11, n. 3, p. 159-163, 2016.

Freitas, S. et al. Flavonoids inhibit angiogenic cytokine production by Human Glioma Cells. Phytotherapy Research, v. 25, p. 916-921, 2011.

Garrido Pinheiro, C. et al. Efeito da assepsia superficial na germinação e incidência de fungos em sementes de espécies florestais. Pesquisa Florestal Brasileira, v. 36, n. 87, p. 253, 2016. http://dx.doi.org/10.4336/2016.pfb.36.87.1234.

Gomes-Copeland, K. K. P. et al. In vitro callogenesis of Poincianella pyramidalis (catingueira). Revista Brasileira de Farmacognosia, v. 27, n. 4, p. 525-528, 2017.

Gonçalves, A. C. et al. Estrutura genética espacial em populações naturais de Dimorphandra mollis (Fabaceae) na região norte de Minas Gerais, Brasil. Revista Brasileira Botânica, v. 2, p. 325-332, 2010.

Guimarães, L. G. de L. et al. Atividades antioxidante e fungitóxica do óleo essencial de capim-limão e do citral. Revista Ciência Agronômica, v. 42, n. 2, p. 464-472, 2011.

Jha, A. K. et al. Micropropagation of Sesbania rostrata from the cotyledonary node. Biologia Plantarum, v. 48, n. 2, p. 289-292, 2004.

Kasmi, M. et al. Effectiveness of aqueous extracts of aromatic and medicinal plants against tomato grey mould in Morocco. Comptes Rendus - Biologies, v. 340, n. 8, p. 386-393, 2017. http://dx.doi. org/10.1016/j.crvi.2017.07.010.

$\mathrm{Ku}, \mathrm{S}$. et al. Inhibitory effects of rutin on the endothelial Protein $\mathrm{C}$ receptor shedding In vitro and In Vivo. Inflammation, 2014. http:// dx.doi.org/10.1007/s10753-014-9866-5.

Machado, T. F. et al. Atividade antimicrobiana do óleo essencial do capim limão ( Cymbopogon citratus ) e sua interação com os componentes dos alimentos. Boletim Do Centro de Pesquisa de Processamento de Alimentos, v. 331, p. 30-38, 2015.

Maguire, J. D. Speed of germination-aid in selection and evaluation for seedling emergence and vigor. Crop Science, v. 2, n. 1, p. 176-177, 1962.

Mascaraque, C. et al. Rutin has intestinal antiinflammatory effects in the $\mathrm{CD}^{4+} \mathrm{CD} 62 \mathrm{~L}^{+} \mathrm{T}$ cell transfer model of colitis. Pharmacological Research, v. 90, p. 48-57, 2014. http://dx.doi.org/10.1016/j. phrs.2014.09.005.

Miranda, C. A. S. F. et al. Óleos essenciais de folhas de diversas espécies: propriedades antioxidantes e antibacterianas no crescimento espécies patogênicas. Revista Ciência Agronômica, n. 47, n. 1, 213-220, 2016. http://dx.doi.org/10.5935/1806-6690.20160025.

Mirghani, M. E. S. et al. Bioactivity analysis of lemongrass (Cymbopogan citratus) essential oil. International Food Research Journal, v. 19, n. 2, p. 569-575, 2012.

Murashige, T. \& Skoog, F. A revised medium for rapid growth and bioassays with tobacco tissue cultures. Plant Physiology, v. 15, p. 473-497, 1962.

Nascimento, P. K. V. et al. Desinfestação e germinação in vitro de sementes de Parapiptadenia rigida Bentham (Brenam). Revista Brasileira de Biociências, p. 141-143, 2007. 
Nunes, J. D. et al. O extrativismo da fava d'anta (Dimorphandra mollis Benth.) na região do Norte de Minas. Revista Brasileira de Plantas Medicinais, v. 14, n. 2, p. 370-375, 2012.

Oliveira, L. S. de et al. Micropropagação de espécies florestais brasileiras. Pesquisa Florestal Brasileira, v. 33, n. 76, p. 439-453, 2013. http://dx.doi.org/10.4336/2013.pfb.33.76.481.

Pereira, R. S. et al. Antibacterial activity of essential oils on microorganisms isolated from urinary tract infection. Revista Saúde Pública, v. 38, n. 2, p. 2003-2005, 2004. http://dx.doi.org/10.1590/ S0034-89102004000200025.

Raut, J. S. \& Karuppayil, S. M. A status review on the medicinal properties of essential oils. Industrial Crops and Products, n. 62, p. 250-264, 2014. https://doi.org/10.1016/j.indcrop.2014.05.055.

Resende, C. F. et al. In vitro propagation and acclimatization of Lippia rotundifolia, an endemic species of Brazilian campos rupestres. Revista Ciencia Agronomica, v. 46, n. 3, p. 582-589, 2015. http:// dx.doi.org/10.5935/1806-6690.20150041.

Righeto, M. V. L. et al. Morfofisiologia de plântulas de Catteya labiata Lindley e Cattleya eldorado Linden cultivadas in vitro sob influencia de paclobutrazol. Revista Brasileira de Biosciencias, v. 10, n. 1, p. 20-25, 2012.

Santos, A. et al. Determinação do rendimento e atividade antimicrobiana do óleo essencial de Cymbopogon citratus (DC.) Stapf em função de sazonalidade e consorciamento. Revista Brasileira de Farmacognosia, v. 19, p. 436-441, 2009.

Scalon, S. de P. Q. et al. Potencial germinativo de sementes de Dimorphandra mollis Benth. em armazenamento, tratamentos pré-germinativos e temperatura de incubação. Cerne, v. 13, n. 3, p. 321-328, 2007. http://dx.doi.org/10.1093/aob/mcw096.

Sharma, A. et al. Antifungal activities of selected essential oils against Fusarium oxysporum $\mathrm{f}$. sp . lycopersici 1322 , with emphasis on Syzygium aromaticum essential oil. Journal of Bioscience and Bioengineering, v. 123, n. 3, p. 308-313, 2017. http://dx.doi. org/10.1016/j.jbiosc.2016.09.011.

Silva, T. I. da et al. Influência do período de secagem e horário de colheita no teor de óleo essencial de Lippia alba (MILL.). Caderno de Ciência e Cultura, v. 15, n. 1, 2016. http://dx.doi.org/ 10.14295/ cad.cult.cienc.v15i1.1029.
Souza, D. S. et al. Atividade antimicrobiana do óleo essencial de Lippia origanoides e Lippia rotundifolia frente a enterobactérias isoladas de aves. Arquivo Brasileiro de Medicina Veterinária e Zootecnia, v. 67, n. 3, p. 940-944, 2015.

Souza, H. A. V. et al. A large historical refugium explains spatial patterns of genetic diversity in a Neotropical savanna tree species. Annals of Botany, v. 119, p. 239-252, 2017. http://dx.doi. org/10.1093/aob/mcw096.

Tangarife-Castaño, V. et al. Antifungal activity of Verbenaceae and Labiatae families essential oils. Pharmacology Online, v. 135, p. 133-145, 2012.

Teixeira, J. A. et al. Red sandalwood ( Pterocarpus santalinus L . f.): biology , importance, propagation and micropropagation. Journal of Forestry Research, v. 30, n. 1, p.745-754, 2018. http://dx.doi. org/10.1007/s11676-018-0714-6.

Trueman, S. J. et al. Tissue Culture of Corymbia and Eucalyptus. Forests, v. 9, n. 84, p. 1-42, 2018. http://dx.doi.org/10.3390/ f9020084.

UFV. Universidade Federal de Viçosa. Sistema para análise estatística. Viçosa, MG, 2017. Disponível em: http://arquivo.ufv. br/saeg/saeg31.htm. Acesso em: 5 set. 2017.

Vicente, M. A. A. et al. Multiplicação in vitro e aclimatação de Vernonia condensata Baker. Revista Brasileira de Plantas Medicinais, v. 11, n. 2, p. 176-183, 2009.

Xie, Y. et al. Antifungal activity of several essential oils and major components against wood-rot fungi. Industrial Crops \& Products, v. 108, p. 278-285, 2017. http://dx.doi.org/ 10.1016/j. indcrop.2017.06.041.

Yarra, R. et al. In vitro conservation and genetic homogeneity assessment of Butea monosperma (Lam.) Taub. Var. lutea (Witt.) Maheshwari: a potential pharmaceutical legume tree. Journal of Dermatological Science, v. 3, n. 4, 195-199, 2016. 